\title{
Research on elecctro-sorption method for air conditioning system with binary solution
}

\author{
Chenchen $\mathrm{Li}^{1, \mathrm{a}}$, Xiuwei $\mathrm{Li}^{1, \mathrm{~b}^{*}}$, Yonghang $\mathrm{Li}^{\mathrm{2}, \mathrm{c}}$ \\ ${ }^{1}$ School of Energy and Power Engineering, Nanjing University of Science and Technology, 210094 Nanjing, China \\ 2 Tianjin TEDA Construction Group CO. LTD, 300457 Tianjin, China
}

\begin{abstract}
Absorption air-conditioning system is a green air-conditioning system. With binary solution as the working fluid, the system performance is better with lower cost. To further improve the efficiency, an electrosorption method is proposed to regenerate the absorbent solution. Its principle is similar to capacitive deionization. The system with $\mathrm{LiBr}-\mathrm{CaCl}_{2}$ has been confirmed in the improvement of performance, while the cost-effectiveness wasn't ideal to satisfy the need of some cases. To solve this problem, the system with $\mathrm{MgCl}_{2}-\mathrm{CaCl}_{2}$ is proposed to analyze the enhancement in the cost-effectiveness. The theoretical and experimental results verify the advantage in the cost-effectiveness compared to the system with $\mathrm{LiBr}-\mathrm{CaCl}_{2}$. Although the performance of the system with $\mathrm{MgCl}_{2}-\mathrm{CaCl}_{2}$ is lower than the other mixed solution, the actual COP could reach 1.9, which is still better than the system with single absorbents. Meanwhile, the energy recovery characteristic could further enhance the advantage in the improvement of performance for the system with $\mathrm{LiBr}-\mathrm{CaCl}_{2}$ and make up the weakness of the system with $\mathrm{MgCl}_{2}-\mathrm{CaCl}_{2}$ solution. The exploration of higher energy recovery efficiency will further improve the competitiveness of the system.
\end{abstract}

\section{Introduction}

At present, energy conservation and emission reduction have attracted people's attention in daily life. It has been revealed that the energy consumption of buildings takes up $36 \%$ of global energy consumption and $39 \%$ of global greenhouse gas emissions [1]. Besides, the energy consumption of air-conditioning system occupies $1 / 3$ of that of buildings [2]. Therefore, it's necessary to develop a green and efficient air-conditioning system. Driven by renewable energy and use water as refrigerant, absorption air-conditioning system can be a great choice [3].

However, its application is limited by the lower performance. To overcome this drawback, many efforts have been made. Variable-effect absorption system has been researched [4]. Absorption/compression hybrid system also has been proposed [5]. Some researches have also been done to seek the alternative of the working fluid $[6,7]$. However, the performance is still not ideal enough due to the heat loss in the thermal regeneration process. To solve this problem, a capacitive deionization (CDI) regeneration method was proposed $[8,9]$. The $\mathrm{COP}$ of the system could reach 2 under certain conditions [9]. Meanwhile, energy recovery characteristic is an advantage of this system. When ions are adsorbed on the electrode, some input energy can be stored and the stored energy can be reused [10].

In the previous research, the complete theoretical and experimental research has been done for the system with $\mathrm{LiCl}$ solution [8-11]. Besides, the performance analysis of the system with different single absorbents has been conducted. The system with $\mathrm{LiBr}$ solution presented the best performance [12]. However, the system with $\mathrm{CaCl}_{2}$ presented better cost-effectiveness, which revealed a contradiction between the performance and cost of single absorbents. To solve this problem, Feng Cheng et al. [12] attempted to take $\mathrm{LiBr}-\mathrm{CaCl}_{2}$ solution as an example to investigate the influence of the added $\mathrm{LiBr}$ to the performance and cost of the system with $\mathrm{CaCl}_{2}$. The results showed a better performance [12]. However, this improvement on the performance came at the cost of low cost-effectiveness. Nevertheless, in some cases where the priority of the cost is higher than the performance of the system, the method to improve the cost-effectiveness is also worthy to be researched. Besides, although preliminary analysis has been made on the energy recovery of the system with $\mathrm{LiCl}$ solution [11], energy recovery is still another important but neglected part of the research on the system with binary solution.

This paper takes $\mathrm{MgCl}_{2}-\mathrm{CaCl}_{2}$ and $\mathrm{LiBr}-\mathrm{CaCl}_{2}$ as an example to analyze and compare the performance and cost-effectiveness of the system with binary working fluid. Analysis has been made based on the developed energy and mass models. The theoretical COP of the system and the effect of energy recovery on the performance have been obtained. Experimental research has been made to reveal the actual regeneration performance. Actual energy recovery characteristic of binary solution has also been confirmed based on the experiments. Moreover, the economic analysis of binary working fluid has been made

* Corresponding author: ${ }^{b}$ good3000best@163.com 
based on the theoretical and experimental results to explore the cost-effectiveness of the system. The results obtained and presented in this paper are meaningful to provide reference for the system with single absorbents to improve its performance or cost-effectiveness.

\section{Materials and Methods}

\subsection{Introduction of the CDI absorption system}

The principle of the electro-sorption method is similar to capacitive deionization (CDI), which has been widely recognized as a water treatment method [8]. Based on the principle of capacitive deionization, a CDI regeneration method for absorption air-conditioning system is proposed.
Compared with the conventional system, the absorbent regeneration process replaces the generator and absorber with two CDI units, while the absorption and evaporation processes are the same as the traditional system [9]. Fig 1 shows the working principle of the proposed system. CDI unit 1 first works as a regenerator where electrodes are saturated with ions. When the weak solution flows into unit 1 , ions are released into the solution. The solution gets strong and flows into the absorber. CDI unit 2 works as deionizer. When the strong solution flows from Tank 2 into unit 2 constantly, ions are adsorbed on electrodes. After many turns, all ions on the electrodes of unit 1 are released and the electrodes of unit 2 are saturated with adsorbed ions. Then CDI unit 1 and 2 will alternate their roles. By this means, this system will acquire strong solution and pure water continually.

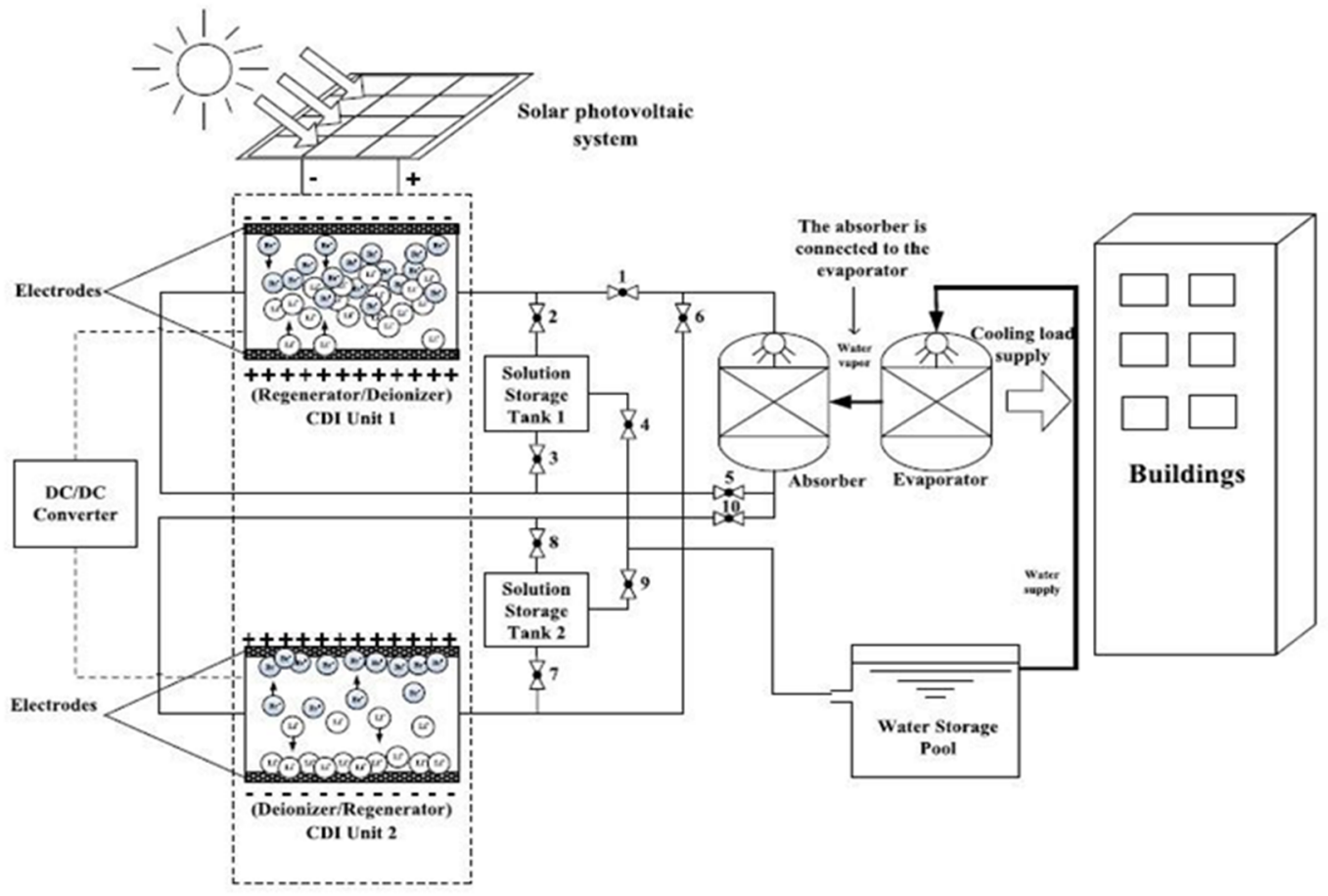

Fig 1. Brief presentation of the CDI based absorption air-conditioning system.

\subsection{Mass and energy models of the system}

In the modeling process, we take $\mathrm{LiBr}-\mathrm{CaCl}_{2}$ as an example to build the mass and energy models. The ions released from electrodes can be expressed as:

$$
\begin{aligned}
\Delta \mathrm{m}_{\mathrm{s}, \mathrm{LiBr}} & =\frac{\mathrm{Con}_{\mathrm{LiBr}, 1}}{\left(1-\operatorname{Con}_{\mathrm{LiBr}, 1}-\operatorname{Con}_{\mathrm{CaCl}_{2}, 1}\right)} \Delta m_{w} \\
\Delta \mathrm{m}_{s, \mathrm{CaCl}} & =\frac{\mathrm{Con}_{\mathrm{CaCl}_{2}, 1}}{\left(1-\mathrm{Con}_{\mathrm{LiBr}, 1}-\mathrm{Con}_{\mathrm{CaCl}_{2}, 1}\right)} \Delta m_{w}
\end{aligned}
$$

The energy supplied can be expressed as:

$$
P_{\mathrm{de}}=U I=\frac{F U Z_{L^{+}} \Delta m_{s, L i B r}}{\lambda M_{s, L i B r}}+\frac{F U Z_{\mathrm{Ca}^{2+}} \Delta \mathrm{m}_{\mathrm{s}, \mathrm{CaCl}_{2}}}{\lambda M_{s, C a C l_{2}}}
$$

Considering the energy recovery ratio $\eta$, the coefficient of performance could be written as:

$$
C O P=\frac{E_{\mathrm{cool}}}{P_{C D I}}=\left[\frac{l_{w} \lambda}{F U(1-\eta)}\right]\left(\frac{1-\operatorname{Con}_{\mathrm{LiBr}, 1}-\operatorname{Con}_{\mathrm{CaCl}_{2}, 1}}{\frac{Z_{L^{+}} \operatorname{Con}_{\mathrm{LiBr}, 1}}{M_{s, L i B r}}+\frac{Z_{\mathrm{Ca}^{2+}} \operatorname{Con}_{\mathrm{CaCl}_{2}, 1}}{M_{s, \mathrm{CaCl} l_{2}}}}\right)
$$

\subsection{Economic analysis models of the system}

Cost-effectiveness is used to make the economic analysis of the system with mixed solutions, and it can be expressed as:

$$
\operatorname{Cos} \mathrm{t}-\text { effectiveness }=\frac{C O P}{\operatorname{Cos} t_{s}}
$$

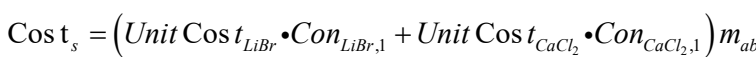

$U$ nit $\operatorname{Cos} t_{L i B r}$ is the price of $L i B r$ per kilogram; $U$ nit $\operatorname{Cos} t_{\mathrm{CaCl}_{2}}$ is the price of $\mathrm{CaCl}_{2}$ per kilogram. Table 1 lists the prices of the absorbents per kilogram in china. 
Table 1. Prices of absorbents.

\begin{tabular}{|c|c|c|c|}
\hline Solute & $\mathrm{LiBr}$ & $\mathrm{CaCl}_{2}$ & $\mathrm{MgCl}_{2}$ \\
\hline Price (Yuan/kg) & 300 & 23 & 16 \\
\hline
\end{tabular}

\subsection{Experimental system}

\subsubsection{Experiments of adsorption characteristic}

An experimental system was designed to conduct experiments, which is displayed in Fig 2. The conductive meter was used to observe the variation of the solution and a storage tank was used to measure the volume and the concentration of the solution. Besides, the current was recorded at intervals of $30 \mathrm{~s}$ and the voltage remained constant at $1.2 \mathrm{~V}$ to calculate the energy supply. The main equipment of the experimental system is shown in Table 2.

Table 2. Main equipment.

\begin{tabular}{|l|l|l|}
\hline Equipment & Model & Accuracy \\
\hline CDI unit & CDI-S10 & \\
\hline Conductivity meter & DDK-210 & $\pm 0.5 \%$ \\
\hline Ion concentration meter & Bante- 320 & $\pm 0.5 \%$ \\
\hline
\end{tabular}

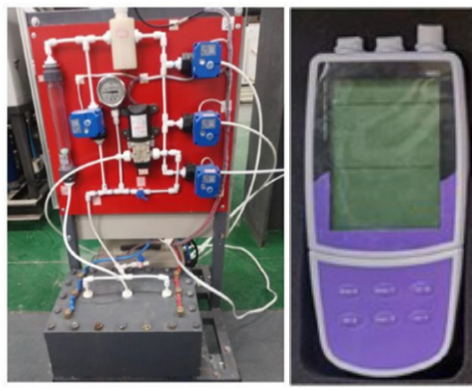

Fig 2. Experimental equipment.

\subsubsection{Experimental system of the energy recovery}

Several steps were first taken to fabricate CDI units. The detailed procedure is shown in Fig 3(a)-(d).

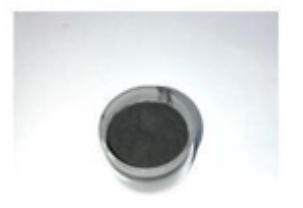

(a)

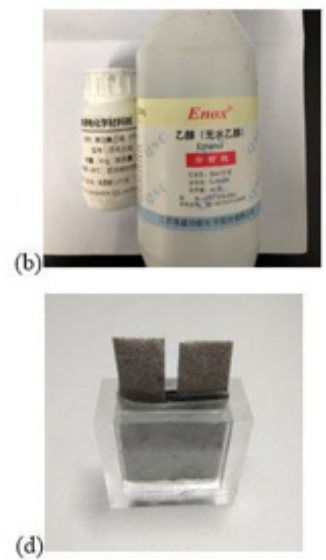

Fig 3. (a). Electrode materials. (b). Mixed materials. (c) Electrode sheet. (d) Manmade CDI unit.

After the CDI units had been fabricated carefully with mixed materials and were placed in a plexiglass container, the units were connected with a DC stabilized voltage supply and multi-function digital multimeter. The experimental platform is displayed in Fig 4 and the specified models of the equipment are shown in Table 3.

Table 3. Specifications of equipment.

\begin{tabular}{|c|c|}
\hline Equipment & Model and accuracy \\
\hline Digital multimeter & DT9205M, $\pm 0.5 \%$ \\
\hline DC stabilized voltage supply & MP $1350 \mathrm{D}, \pm 1 \%$ \\
\hline
\end{tabular}

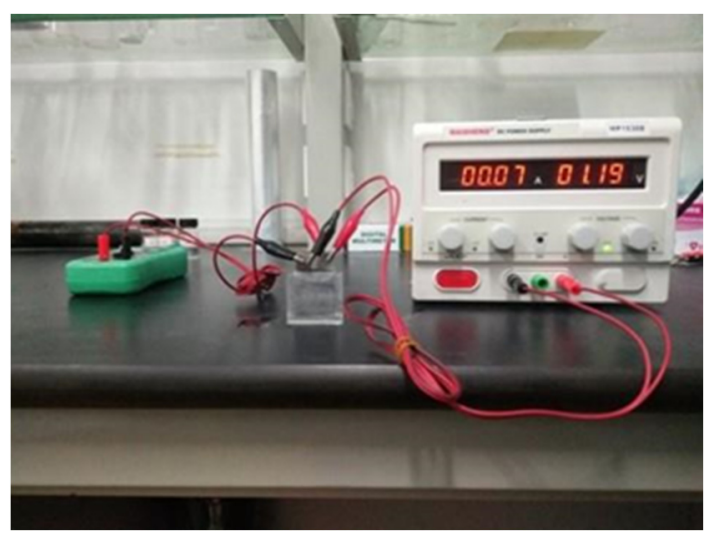

Fig 4. Charging and discharging test

\section{Results \& Discussion}

\subsection{Theoretical analysis}

\subsubsection{Theoretical performance of the system}

With Eq. (4), the theoretical performance of the system could be analyzed. The parameters are listed in the Table 4. The results are shown in Fig 5.

Table 4. Calculated parameters.

\begin{tabular}{|c|c|c|}
\hline Parameter & Value & Reference \\
\hline$U$ & $1.2 \mathrm{~V}$ & Experimental data \\
\hline$\lambda$ & $50 \%$ & Typical CDI product [13] \\
\hline$\eta$ & $50 \%$ & \\
\hline
\end{tabular}

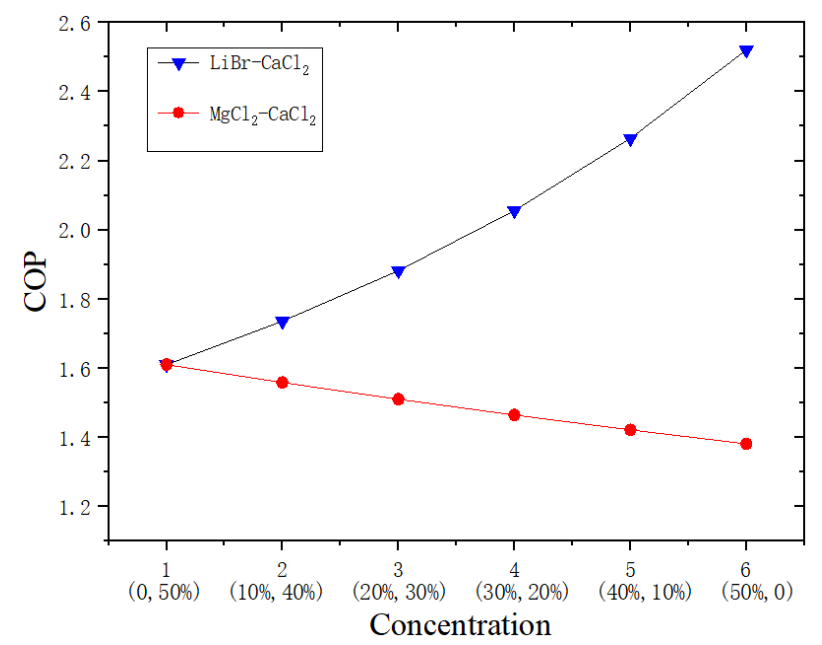

Fig 5. Theoretical COP with two different mixed solutions. 
The results show that the COP of the system with $\mathrm{LiBr}$ $\mathrm{CaCl}_{2}$ is obviously higher than the system with $\mathrm{CaCl}_{2}$. While the COP of the system with $\mathrm{MgCl}_{2}-\mathrm{CaCl}_{2}$ decreases a little, which reduces from 1.6 to 1.4. So, when the other absorbents are mixed with $\mathrm{CaCl}_{2}$, the $\mathrm{COP}$ is higher with higher ratio of the more influential single absorbent in the binary solution.

\subsubsection{Theoretical economic analysis}

Based on the theoretical performance, the theoretical economic analysis was conducted. With Eqs. (5) and (6), the calculated results are given in Fig 6.

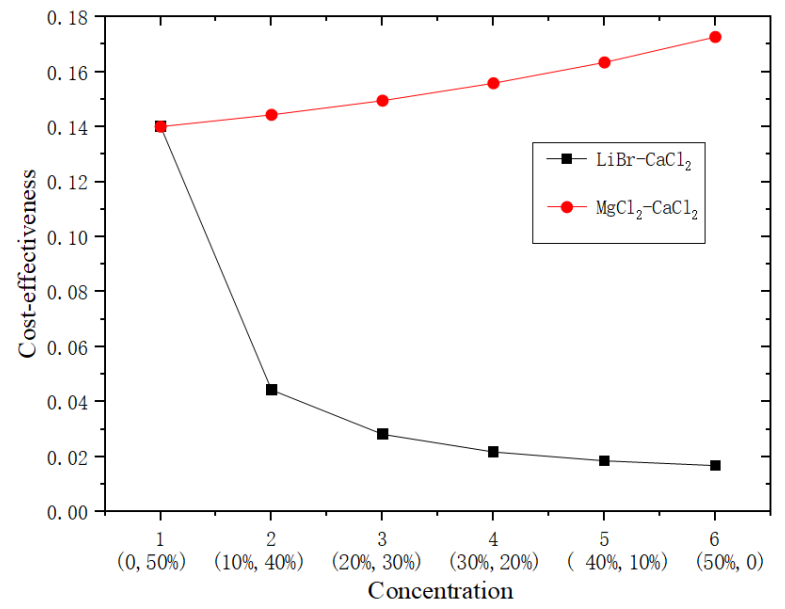

Fig 6. Cost-effectiveness of the system with mixed solution.

Although the COP of the system with $\mathrm{MgCl}_{2}-\mathrm{CaCl}_{2}$ is lower than the system with $\mathrm{LiBr}-\mathrm{CaCl}_{2}$, the system with $\mathrm{MgCl}_{2}-\mathrm{CaCl}_{2}$ has better cost-effectiveness due to the low price of the two single absorbents, which means that higher COP can be obtained at unit cost.

\subsubsection{Theoretical effect of energy recovery ratio}

According to the analysis of Eq. (4), we took $50 \%$ as the total concentration to reveal the theoretical effect of the energy recovery on the COP of the system.

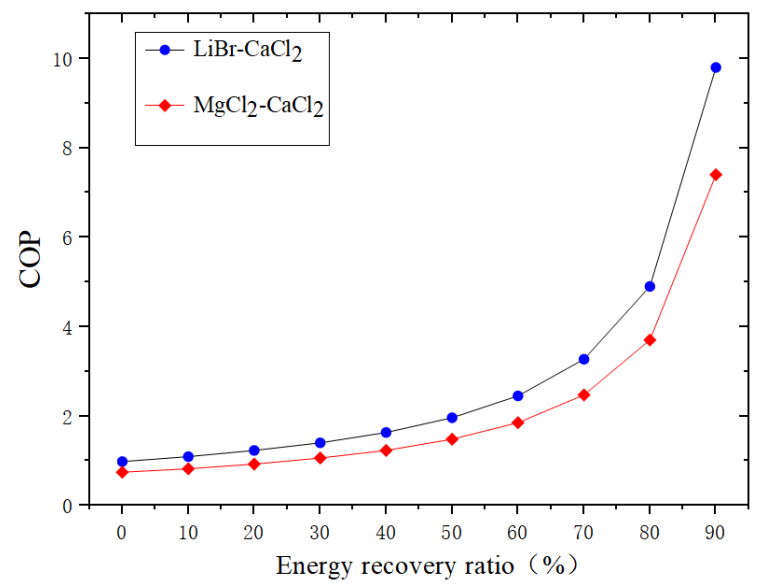

Fig 7. The COP of the system with energy recovery ratio.
With the help of the energy recovery, the COP of the system with $\mathrm{MgCl}_{2}-\mathrm{CaCl}_{2}$ could reach 3 at the ratio of $80 \%$, which implies a great potential to further improve the performance of the system with high cost-effective to enhance its competitiveness.

\subsection{Experimental analysis}

\subsubsection{Experimental performance of the system}

After acquiring the volume and concentration of different ions of regenerated solution, as well as the energy consumption, with Eqs. (1)、(2) and (4), the actual COP of the system with mixed solution can be acquired. The results are given in Fig 8.

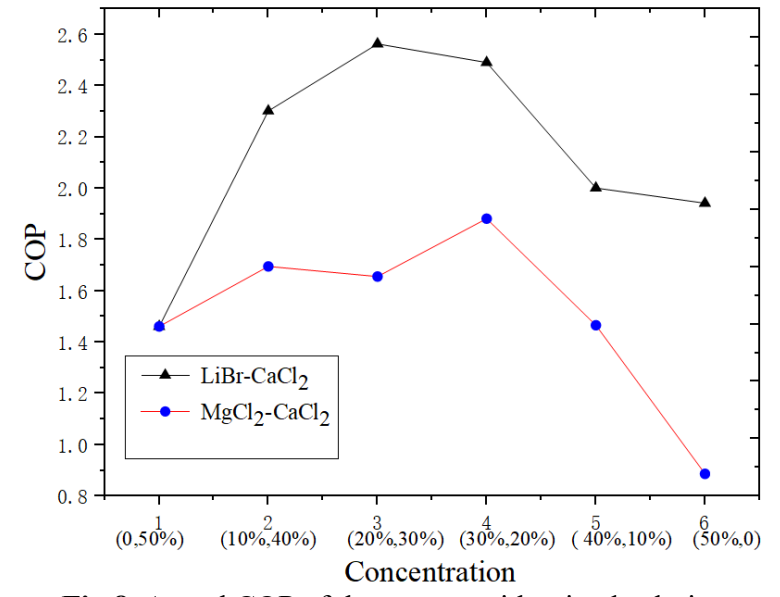

Fig 8. Actual COP of the system with mixed solution.

For the system with $\mathrm{MgCl}_{2}-\mathrm{CaCl}_{2}$, the actual COP can reach its highest value when the concentration ratio is $(30 \%, 20 \%)$. Although the COP of the system with $\mathrm{MgCl}_{2}-$ $\mathrm{CaCl}_{2}$ is still lower than the other mixed solution, the actual performance is much better than the system with $\mathrm{CaCl}_{2}$, which implies the improvement of the binary solution in the practical application.

\subsubsection{Economic analysis based on the experiments}

Based on the actual COP acquired, the economic analysis on the cost-effectiveness could be given in Fig 9.

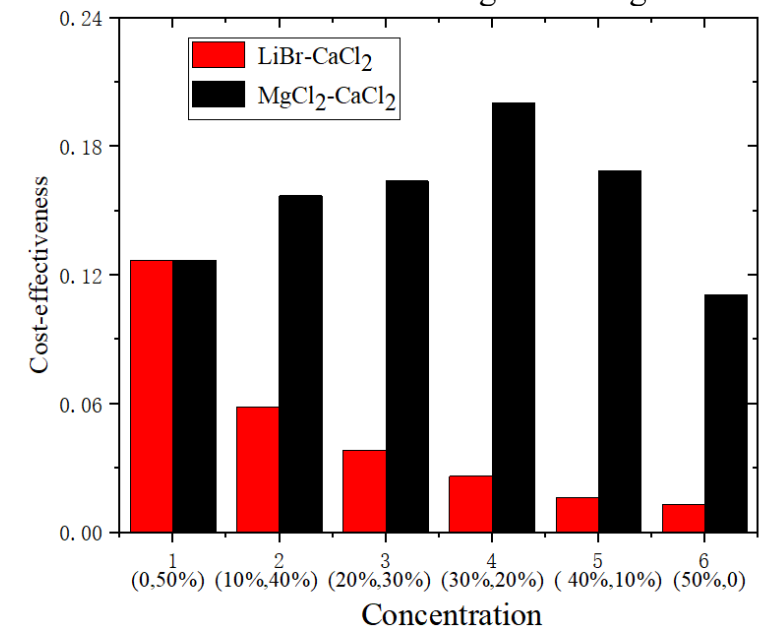

Fig 9. Cost-effectiveness based on the experimental data. 
For the system with $\mathrm{LiBr}-\mathrm{CaCl}_{2}$, the addition of $\mathrm{LiBr}$ still do harm to the cost-effectiveness of the system. Meanwhile, when the concentration ratio is $(30 \%, 20 \%)$, the actual COP and the cost-effectiveness of the system with $\mathrm{MgCl}_{2}-\mathrm{CaCl}_{2}$ reach the highest value at the same time.

\subsubsection{Experimental research of energy recovery ratio}

The charging and discharging test were designed to test the actual efficiency. The final results are shown in Fig 10. When the concentration ratio of $\mathrm{LiBr}-\mathrm{CaCl}_{2}$ solution is $(20 \%, 30 \%)$, the highest COP of the system could reach 2.6 while the energy recovery efficiency just reaches $38 \%$, which means a larger space to improve the performance. Meanwhile, although the performance of the system with $\mathrm{MgCl}_{2}-\mathrm{CaCl}_{2}$ is low, considering the highest efficiency of the system just reaches $20 \%$, this problem will be solved through exploring the potential to improve the energy recovery efficiency.

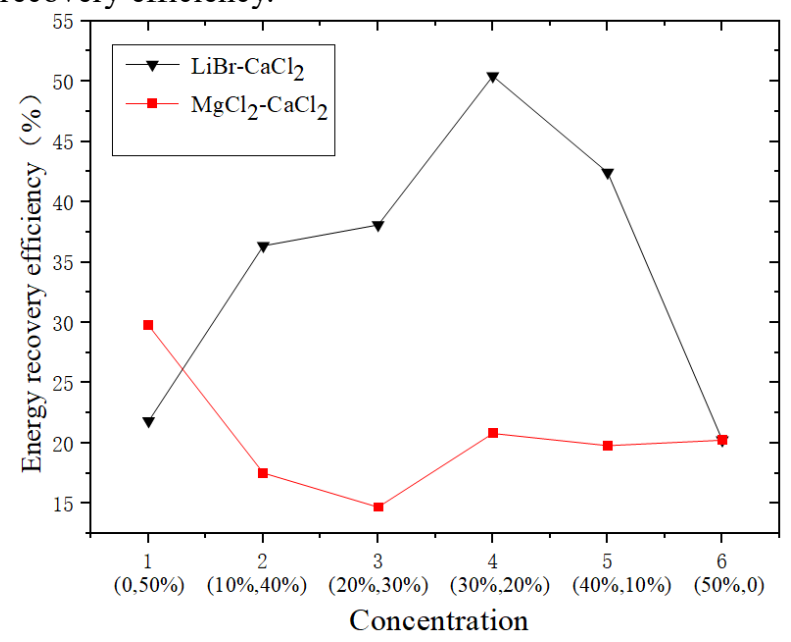

Fig 10. Actual energy recovery efficiency.

\subsection{Discussion}

In this paper, it is found that the system with $\mathrm{MgCl}_{2}-\mathrm{CaCl}_{2}$ solution presents higher cost-effectiveness compared with the system with $\mathrm{LiBr}-\mathrm{CaCl}_{2}$ and the system with single absorbents, which has been confirmed with the theoretical and experimental analysis. Meanwhile, considering the potential to explore the energy recovery efficiency, the lower performance of the system with $\mathrm{MgCl}_{2}-\mathrm{CaCl}_{2}$ could be solved and thus enhances the competitiveness of the system with mixed solutions. Moreover, the other mixed solution consist of the rest of the common single absorbents could be investigated to see their performance and cost-effectiveness to complete the research on the system with different mixed solution.

\section{Conclusions}

Previous research has revealed the improvement on the performance of the system with $\mathrm{LiBr}-\mathrm{CaCl}_{2}$ solution, as well as the weakness of the low cost-effectiveness. In order to make up the weakness to satisfy the need to improve the cost-effectiveness of the system with single absorbents, this paper proposed the system with $\mathrm{MgCl}_{2}-$
$\mathrm{CaCl}_{2}$ solution.

The theoretical COP of the proposed system decreases a little compared to the $\mathrm{COP}$ of the system with $\mathrm{CaCl}_{2}$, which reduces from 1.6 to 1.4. However, the experimental test for the actual COP shows that the COP of the system with $\mathrm{MgCl}_{2}-\mathrm{CaCl}_{2}$ can reach 1.9 when the concentration ratio is $(30 \%, 20 \%)$, which is over the COP of the system with $\mathrm{CaCl}_{2}$.

Based on the economic analysis on the theoretical research and the experimental data, the advantage of the proposed system in good cost-effectiveness has been both confirmed, which implies the system with binary solution could acquire better $\mathrm{COP}$ at lower cost.

Through the analysis on the effect of energy recovery efficiency on the performance, it is found that the exploration of higher efficiency could have a great potential to further enhance the advantage in the improvement of performance for the system with $\mathrm{LiBr}$ $\mathrm{CaCl}_{2}$ and make up the weakness of the system with $\mathrm{MgCl}_{2}-\mathrm{CaCl}_{2}$ solution. Further work will focus on trying to study more hybrid solutions and comparing attempts between systems with different hybrid solutions.

\section{Acknowledgments}

This research was supported by the fund of National Natural Science Foundation of China under the contract No. 51676098. It was also supported by the grants from the fund of Natural Science Foundation of Jiangsu Province under the contracts No. BK20170095 and No. BK20160822.These supports are gratefully acknowledged.

\section{References}

1. Liu, Z.B., Li, W.J., Chen, Y.Z., Luo, Y.Q., Zhang, L. (2019) Review of energy conservation technologies for fresh air supply in zero energy buildings. Appl. Therm. Eng., 148: 544-556.

2. Huo, H., Shao, J.H., Huo, H.B. (2017) Contributions of energy-saving technologies to building energy saving in different climatic regions of China. Appl. Therm. Eng., 124: 1159-1168.

3. Soto, P., Domínguez-Inzunza, L.A., Rivera, W. (2018) Preliminary assessment of a solar absorption air conditioning pilot plant. Case Stud Therm. Eng., 12: 672-676.

4. Li, X., Kan, X., Sun, X.Y., Zhao, Y., Ge, T.S., Dai, Y.J. (2019) Performance analysis of a biomass gasification-based CCHP system integrated with variable-effect $\mathrm{LiBr}-\mathrm{H}_{2} \mathrm{O}$ absorption cooling and desiccant dehumidification. Energy, 176: 961-979.

5. Li, J.B., Xu, S.M., Kong, X.Q., Liu, K., Cui, F.L. (2019) Experimental study on absorption/compression hybrid refrigeration cycle. Energy, 168: 1237-1245.

6. Kadam, S.T., Gkouletsos, D., Hassan, I., Rahman, M.A., Kyriakides, A.S., Papadopoulos, A.I. (2020) Investigation of binary, ternary and quaternary mixtures across solution heat exchanger used in 
absorption refrigeration and process modifications to improve cycle performance. Energy, 198: 117254.

7. Kühn, R., Meyer, T., Ziegler, F. (2020) Experimental investigation of ionic liquids as substitute for lithium bromide in water absorption chillers. Energy, 205: 117990.

8. Li, X.W., Zhang, X.S., Wang, H., Zhang, Z. (2016) Capacitive deionization regeneration as a possible improvement of membrane regeneration method for absorption air-conditioning system. Appl. Energy., 171: 405-414.

9. Li, X.W., Zhang, X.S., Wang, H., Zhang, Z. (2016) The potentials of capacitive deionization regeneration method for absorption air-conditioning system. Energy Convers. Manag., 114: 303-311.

10. Andres, G.L., Yoshihara, Y. (2016) A capacitive deionization system with high energy recovery and effective reuse. Energy, 103: 605-617.

11. Zhao, H., Zhang, X.S., Li, X.W., Ding, B.Q., Cheng, F. (2018) Research on actual performance and energy recovery characteristic of capacitive deionization regeneration method for absorption air-conditioning system. Energy Convers. Manag., 171: 1549-1559.

12. Cheng, F., Li, Y.H., Zhang, X.S., Li, X.W. (2020) Effect of different absorbents on actual performance of the absorption air-conditioning system based on capacitive deionization regeneration method. Appl. Therm. Eng., 172: 115130.

13. AlMarzooqi, F.A., Al Ghaferi, I., Hilal Saadat, N. (2014) Application of capacitive deionization in water desalination: a review. Desalination, 342: 3-15. 